\title{
NOUVELLE
}

\section{Compensation génétique en pathologie humaine}

Simone Gilgenkrantz

Médecine/Sciences,

9 , rue Basse,

54330 Clérey-sur-Brénon, France.

simone.gilgenkrantz@club-internet.fr
> Parmi les syndromes microdélétionnels, le syndrome de délétion 22q11.2 (22qll.DS) est l'un des plus fréquents (1/4 000 naissances environ). II se traduit cliniquement par un éventail de malformations cardiaques et faciales qui vont du syndrome de diGeorge au syndrome cardiovélofacial, d'où l'acronyme DGS/VCFS. L'étude de la région délétée, de $3 \mathrm{Mb}$ environ dans la plupart des cas, a permis de comprendre la fréquence des recombinaisons homologues non alléliques (RHNA) qui se produisent pendant la méiose [1] : elle est en effet constituée de séquences dupliquées de LCR (low copy repeats) qui favorisent ces recombinaisons. De ces RHNA peuvent résulter des délétions ou des duplications (Figure 1). Ces dernières sont plus rares et se manifestent par un phénotype recoupant partiellement celui des délétions [2]. Les 22ql1DS sont le plus souvent sporadiques mais dans environ $7 \%$ des cas, l'atteinte est transmise par I'un des parents. Quand ceux-ci sont bien-portants, il est logique de supposer qu'il s'agit d'une délétion de novo. Pourtant un cas très intéressant vient d'être

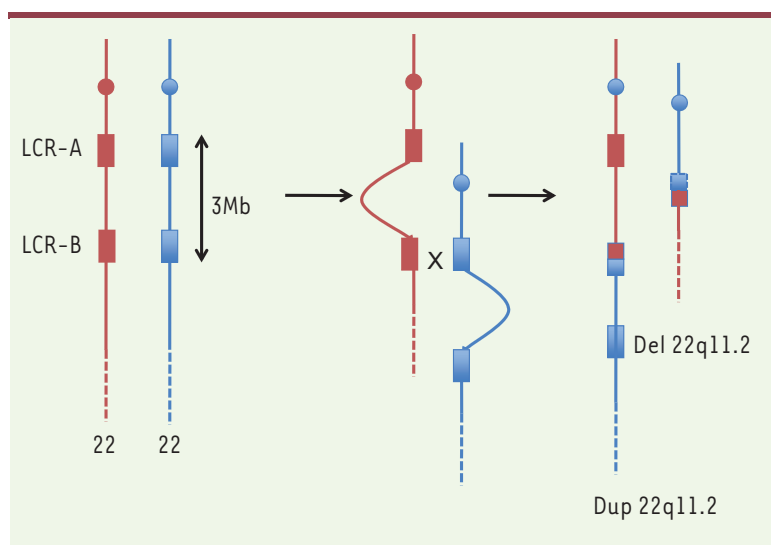

rapporté par un groupe de cytogénéticiens français [3]. Le père d'une fillette atteinte de 22qll DS, phénotypiquement normal, était porteur d'un double remaniement : délétion 22 qll sur l'un de ses chromosomes 22 et duplication de la même région sur l'autre. Le phénotype normal s'explique par une compensation génétique qui a pu être prouvée par l'expression - par PCR transcriptase inverse de chacun des deux gènes $T B X$, visibles en FISH côte à côte sur le même chromosome 22 sur les mitoses et dans les noyaux en interphase. Cette observation atteste d'un mécanisme de compensation génique dans une maladie humaine; effet compensatoire qui a d'ailleurs été préalablement démontré dans un modèle murin sur la région homologue à 22ql1.2 [4]. Elle conduit aussi à se montrer prudent dans le conseil génétique car le risque de déséquilibre (délétion ou duplication) est de $100 \%$ dans la descendance de cet homme. II faudrait donc vérifier que les parents phénotypiquement normaux ont bien un caryotype normal avant de conclure à une absence de risque pour la descendance ultérieure.

L'origine de cette double anomalie chez le père peut s'expliquer par une recombinaison homologue non allélique survenue à la première division méiotique dans un gamète grand-paternel. Le caryotype du grand-

Figure 1. Mécanisme des recombinaisons homologues non alléliques. père s'est en effet révélé normal, mais l'étude des microsatellites des chromosomes 22 de la famille montre que c'est bien sur un chromosome 22 grand-paternel que s'est produit la RHNA. Celle-ci a pu aussi survenir après la fécondation: l'accident post-zygotique au cours des premières divisions du zygote est alors suivi par une répartition sélective de la lignée del/dup 22qll.2 dans le bouton embryonnaire et de la lignée normale dans le cytotrophoblaste. Cette dernière hypothèse est la plus séduisante et corrobore les cas assez fréquents en diagnostic prénatal où des caryotypes différents sont observés entre villosités choriales et tissus fœtaux [5]. $\diamond$

Genetic compensation

in human pathology

\section{RÉFÉRENCES}

1. Shaikh TH, Kurahashi H, Saitta SC, et al. Chromosome 22-specific low copy repeats and the 22ql1.2 deletion syndrome : genomic organization and deletion endpoint analysis. Hum Mol Genet 2000 ; 9 : 489-501.

2. Portnoï MF, Lebas F, Gruchy N, et al. 22q11.2 duplication syndrome : two new familial cases with some overlapping features with DiGeorge/ velocardiofacial syndromes. Am J Med Genet 2005; $137: 47-51$.

3. Carelle-Calmels N, Saugier-Veber P, Girard-Lemaire $\mathrm{F}$, et al. Genetic compensation in a human genomic disorder. N Engl J Med 2009 ; 360 : 1211-6.

4. Lindsay $\varepsilon A$, Botta A, Jurecic V, et al. Congenital heart disease in mice deficient for the DiGeorge syndrome region. Nature $1999 ; 401: 379-83$.

5. Crane JP, Cheung SV. An embryogenic model to explain cytogenetic inconsistencies observed in chorionic villus versus fetal tissue. Prenat Diagn $1988 ; 8$ : 119-29. 